This is a postprint version of the following published document:

Tapetado, A.; Pinzon, P.J.; Zubia, J.; Vazquez, C. Polymer Optical Fiber Temperature Sensor With Dual-Wavelength Compensation of Power Fluctuations. IEEE Journal of Lightwave Technology, 33 (2015) 13, pp. 2716 - 2723 . Available in http://www.dx.doi.org/10.1109/JLT.2015.2408368

(C) 2015. IEEE. Personal use of this material is permitted. Permission from IEEE must be obtained for all other uses, in any current or future media, including reprinting/republishing this material for advertising or promotional purposes, creating new collective works, for resale or redistribution to servers or lists, or reuse of any copyrighted component of this work in other works. 


\title{
Polymer Optical Fiber Temperature Sensor With Dual- Wavelength Compensation of Power Fluctuations
}

\author{
A. Tapetado, P. J. Pinzón, J. Zubia, and C. Vázquez
}

\begin{abstract}
The design and development of a plastic optical fiber macrobend temperature sensor is presented. The sensor can op-erate in a temperature range from -55 to $70{ }^{\circ} \mathrm{C}$ and has a linear response versus temperature with a sensitivity of $8.95 \cdot 10-4{ }^{\circ} \mathrm{C}-1$. The sensor system uses the ratio of transmittance at two wave-lengths to implement a selfreferencing technique in order to avoid undesirable power fluctuations influence. The transmittance ratio precision is $0.1 \%$. An analysis has been developed to find the two wavelengths which ratio offers the highest linearity and sensitiv-ity response. Experimental results are successfully compared with theoretical approaches.
\end{abstract}

Key Words: Bend loss, intensity, loop, macro-bend, POF sen-sor, self-referencing technique, temperature, WDM.

\section{Introduction}

The use of temperature sensors in today's society is continually growing. There are a large number of sectors in which a temperature sensor is necessary to control different processes, such as: the automotive industry, air-conditioning control, food industry and medical applications, among others. Some decades ago, world sensor market was made up of traditional temperature sensors such as thermocouples, thermistors and resistance temperature detectors. These sensors are not well suited to be used in the presence of electromagnetic disturbances or inflammable atmospheres. These problems together with the advances in fabrication of optical fiber and in low-cost components for optical fiber communications promote the development of innovative temperature sensors based on optical fibers.

Many optical fiber sensors have been developed based on amplitude or phase techniques [1]. Different interferometric configurations have been proposed as temperature sensors such as Mach-Zehnder [2], Fabry-Perot [3] and Michelson [4]. These types of sensors are characterized by their large sensitivity and

This work was supported by the Spanish Ministry of Economía y Competitividad and Madrid region under Grants TEC2012-37983-C03-02, P2013/MIT-2790.

A. Tapetado, P. Pinzón, and C. Vázquez are with the Electronics Technology Department, Universidad Carlos III de Madrid, Madrid 28911, Spain (e-mail: atapetad@ing.uc3m.es; ppinzon@ing.uc3m.es; cvazquez@ing.uc3m.es).

J. Zubia is with the Department of Electronics and Telecommunication, Universidad del País Vasco, Euskal Herriko Unibertsitatea, Bilbao 48013, Spain (e-mail: joseba.zubia@ehu.es). accuracy, but their complexity of implementation and the higher price of the required equipment, make them unsuitable for lowcost applications. On the other hand, amplitude modulation temperature sensors are based on optical power variations. Some proposed sensors are based on frustration of total internal reflections [5]-[7], light generations [8] or light attenuation [9], among others. The amplitude temperature sensors are usually cheaper than the phase modulation sensors but they need to use a self-referencing technique [10]-[14] to avoid false reading caused by light source fluctuations or other undesired losses.

In this paper, the authors propose and characterize a selfreference low-cost intensity macrobend temperature sensor based on polymer optical fiber (POF). Other techniques to measure the temperature with macrobend sensors have been developed using silica [5], [7], [15], [16] or POF [6] but with other self-referencing technique that needs two different physical paths for the reference and sensing signals. The main advantage of using POF fiber instead of glass fiber is the larger diameter of the former, making the sensor less fragile and easier to handle, reducing development and maintenance cost. POF dimensions allow the use of low precision connectors and lenses as well as simple multiplexing and demultiplexing devices, especially if compared with silica optical fiber based sensors, allowing the implementation of low cost sensing systems. Although polymer based sensors have a smaller temperature range.

In this context, the novelty of this work is to develop and implement a self-referencing technique based on a single macrobend loop. The sensor system is based on the ratio of the output transmittances at two different wavelengths in a single macrobend sensor to avoid possible errors related to undesired optical power fluctuations [17]. Using a single macrobend loop instead of a dummy fiber-optic sensor as in [6], provides a robust temperature sensor independent of the repeatability of the manufacturing process and the different physical path loss evolution of other self-referencing techniques.

\section{Principle of operation}

A Step-index (SI) multi-mode optical fiber curved with a bend radius $\mathrm{R}$ and a core diameter $2 \rho_{\text {Core }}$ is shown in Fig. 1 . The core and cladding refractive indices are $\mathrm{n}_{\text {Core }}$ and $\mathrm{n}_{\text {Cladding }}$, respectively. The geometrical approach used to describe the core rays in a planar waveguide [18] is adapted to the bent optical fiber, due to the presence of the skew rays [19].

The guidance of the core rays is achieved by ensuring that the propagation angle, $\alpha$, satisfies the condition: $0 \leq \alpha \leq \alpha_{\mathrm{c}}$, where the critical angle $\left(\alpha_{\mathrm{c}}\right)$ at a specific temperature $(\mathrm{T})$ is 

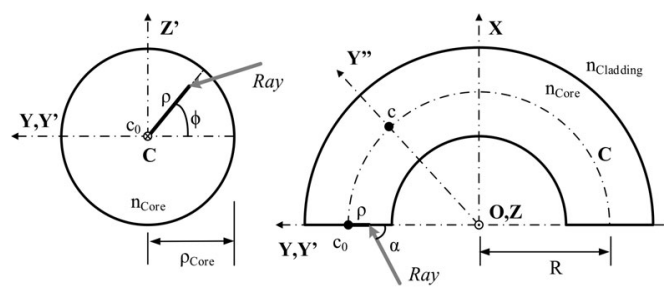

(a)

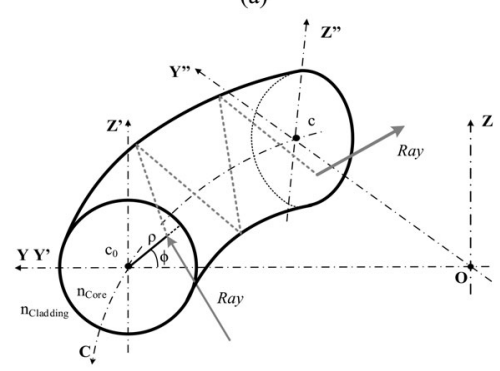

(b)

Fig. 1. Schematic of a bend fiber section curved with a radius of curvature R. (a) Frontal and top view. (b) 3-D section.

given by:

$$
\alpha_{\mathrm{c}}(\mathrm{T})=\sin ^{-1}\left[\frac{\mathrm{n}_{\text {Cladding }}(\mathrm{T})}{\mathrm{n}_{\text {Core }}(\mathrm{T})}\right]
$$

The optical fiber numerical aperture (NA) for the rectilinear region at temperature $\mathrm{T}$ is given by:

$$
\mathrm{NA}(\mathrm{T})=\mathrm{n}_{\text {Core }} \cdot \cos \alpha \leq\left[\mathrm{n}_{\text {Core }}^{2}(\mathrm{~T})-\mathrm{n}_{\text {Cladding }}^{2}(\mathrm{~T})\right]^{1 / 2}
$$

The optical fiber sensor proposed in this paper is based on a macrobend POF. In this intensity sensor, the $\rho$ losses depend on the NA change with the core and cladding refractive index variations. Those refractive indexes depend on the temperature and the wavelength. The optical fiber used in this experiment is a SI POF [20] with polymethylmethacrylate (PMMA) 980 $\mu \mathrm{m}$ core diameter and $1 \mathrm{~mm}$ cladding diameter of fluorinated polymer. The refractive index of the core and cladding can be fitted to a three-term Sellmeier dispersion relation of the form [21]:

$$
\mathrm{n}(\lambda)=\left[1+\sum_{i=1}^{3} \frac{\mathrm{A}_{i} \cdot \lambda^{2}}{\lambda^{2}-l_{i}^{2}}\right.
$$

where $n$ is the core and cladding refractive index, $A_{i}$ is the oscillator strength, $l_{i}$ is the oscillator wavelength, and $\lambda$ is the wavelength of light.

The Sellmeier equation coefficients for a PMMA and a fluorinated polymer as a function of temperature are reported in [22], [23]. From (3), the first term of the Sellmeier coefficients for a fluorinated polymer has been adjusted to obtain the cladding refractive index of the fiber at the conditions given by the manufacturer. The fiber used in this experiment has a cladding refractive index of 1.40 at $25^{\circ} \mathrm{C}$ and $650 \mathrm{~nm}$ [24]. Using the Sellmeier coefficients for the core and cladding material (see Table I) and considering $\mathrm{T}_{0}=27{ }^{\circ} \mathrm{C}$, the NA for the fiber at $25^{\circ} \mathrm{C}$ and $650 \mathrm{~nm}$ is 0.511 . This value is in good agreement
TABLE I

COEFFICIENT OF THE SELlMEIER EQUATION FOR DIFFERENT POLYMERS

\begin{tabular}{lcc}
\hline Coefficient & PMMA & Adjusted fluorinated polymer \\
\hline $\mathrm{A}_{1}$ & 0.4963 & 0.34 \\
$\mathrm{l}_{1}$ & $71.8 \cdot\left(\mathrm{T} / \mathrm{T}_{0}\right)^{2}$ & $79.1 \cdot\left(\mathrm{T} / \mathrm{T}_{0}\right)^{2}$ \\
$\mathrm{~A}_{2}$ & 0.6965 & 0.351 \\
$\mathrm{l}_{2}$ & $117.4 \cdot\left(\mathrm{T} / \mathrm{T}_{0}\right)^{2}$ & $83.81 \cdot\left(\mathrm{T} / \mathrm{T}_{0}\right)^{2}$ \\
$\mathrm{~A}_{3}$ & 0.3223 & 0.25 \\
$\mathrm{l}_{3}$ & $9.237 \cdot\left(\mathrm{T} / \mathrm{T}_{0}\right)^{2}$ & $106 \cdot\left(\mathrm{T} / \mathrm{T}_{0}\right)^{2}$ \\
\hline
\end{tabular}

$\mathrm{T}$ is temperature and $\mathrm{T}_{0}$ is a reference temperature.

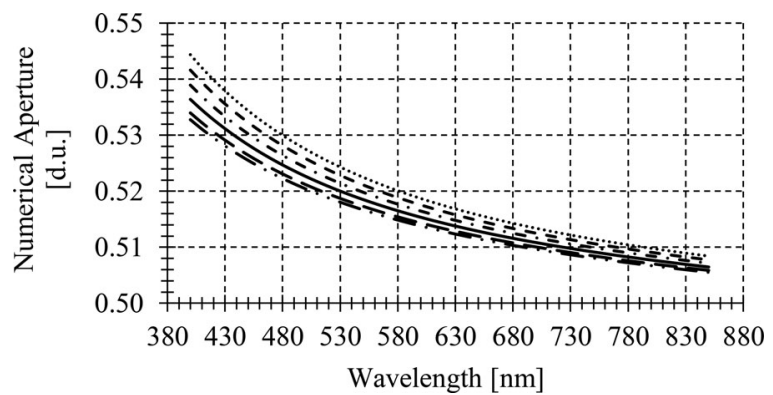

Fig. 2. Local numerical aperture versus wavelength in a rectilinear region of a POF: $-\cdots-25^{\circ} \mathrm{C},--30^{\circ} \mathrm{C},-40^{\circ} \mathrm{C},-\cdot-50{ }^{\circ} \mathrm{C},--60^{\circ} \mathrm{C}, \cdots 70^{\circ} \mathrm{C}$.

with the NA given by the manufacturer, $\mathrm{NA}=0.485 \pm 0.045$ at $25^{\circ} \mathrm{C}$ and $650 \mathrm{~nm}$ [24].

From (2) and (3), and using the core and cladding Sellmeier coefficients, NA in a POF rectilinear region is plotted against wavelength for different temperatures in Fig. 2.

When the optical fiber is bent, the guidance of the core rays can follow two ways. Only the rays entering the bent part of the fiber in the meridional plane remain with the same angle of incidence along a given ray path. On the other hand, the skew rays entering this plane, after the successive reflections within the core, do not follow a simple repeatable pattern because of the asymmetry introduced by bending the fiber. So when the optical fiber is bent, the local NA changes at a given location of the curvature according to [19]:

$$
\begin{aligned}
\mathrm{NA}(\mathrm{R}, \rho, \phi)= & \mathrm{n}_{\text {Core }} \cdot\left[1-\left(\frac{\mathrm{n}_{\text {Cladding }}^{2}}{\mathrm{n}_{\text {Core }}^{2}}\right)\right. \\
& \cdot\left(\frac{\mathrm{R}+\rho_{\text {Core }}}{\mathrm{R}-\rho \cdot \cos \phi}\right]^{2 / 2}
\end{aligned}
$$

where $\phi$ is the ray angle at the beginning of the bend, which varies from $0^{\circ}$ to $180^{\circ}, \rho_{\text {Core }}$ is the fiber core radius and $\rho$ is the radial position in the core satisfying the relation $0 \leq$ $\rho \leq \rho_{\text {Core }}$ (see Fig. 1). Using (3) and (4), and the core and cladding Sellmeier coefficients, the temperature and wavelength dependence of the NA for a bend fiber can be expressed as:

$$
\begin{aligned}
& \mathrm{NA}\left(\mathrm{T}, \lambda, \mathrm{R}, \rho_{\text {Core }}, \phi\right)=\mathrm{n}_{\text {Core }}(\mathrm{T}, \lambda) \cdot \\
& \cdot\left[1-\left(\frac{\mathrm{n}_{\text {Cladding }}^{2}(\mathrm{~T}, \lambda)}{\mathrm{n}_{\text {Core }}^{2}(\mathrm{~T}, \lambda)}\right) \cdot\left(\frac{\mathrm{R}+\rho_{\text {Core }}}{\mathrm{R}-\rho \cdot \cos \phi}{ }^{1 / 2}\right.\right.
\end{aligned}
$$




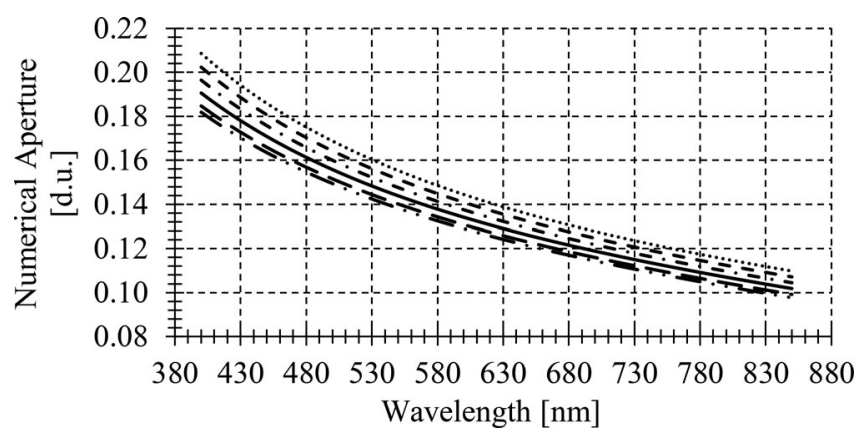

Fig. 3. Local numerical aperture versus wavelength, $\mathrm{R}=2 \mathrm{~mm}, \varphi=135$ and $\rho=490 \mu \mathrm{m}:-\cdots-25^{\circ} \mathrm{C},--30^{\circ} \mathrm{C},-40^{\circ} \mathrm{C},-\cdot-50^{\circ} \mathrm{C},--60^{\circ} \mathrm{C}$, $.70{ }^{\circ} \mathrm{C}$.

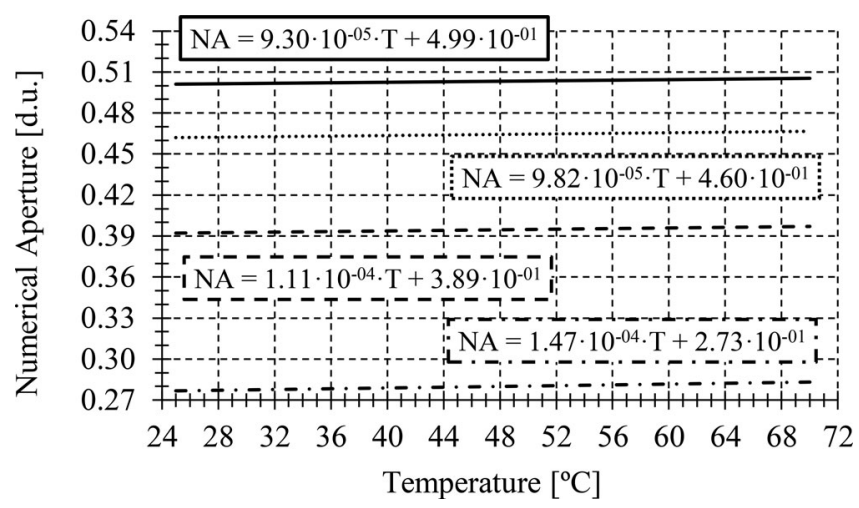

Fig. 4. Local numerical aperture versus temperature, $\lambda=660 \mathrm{~nm}, \varphi=150^{\circ}$ and $\rho=490 \mu \mathrm{m}:-\mathrm{R}=25 \mathrm{~mm}, . \mathrm{R}=5 \mathrm{~mm},--\mathrm{R}=2 \mathrm{~mm},-\cdot-$ $\mathrm{R}=1 \mathrm{~mm}$.

NA in a bend region is plotted against wavelength for different temperatures in Fig. 3, in dimensionless units (d.u.). A bend radius of $2 \mathrm{~mm}$ is considered.

It can be seen that at a given temperature the local NA decreases when the wavelength increases. In addition, the local NA increases when temperature increases. This happens because an optical ray that is unguided at the reference temperature becomes guided at greater temperatures. On the other hand, the NA temperature sensitivity increases when a bend is applied to the optical fiber, as shown in Fig. 2 and Fig. 3, with maximum NA temperature sensitivity of $2.6 \cdot 10^{-4}{ }^{\circ} \mathrm{C}^{-1}$ and $6 \cdot 10^{-4}{ }^{\circ} \mathrm{C}^{-1}$ for an unbent and bent fiber illuminated with a $400 \mathrm{~nm}$ light source, respectively.

From (3) and (4), and using the core and cladding Sellmeier coefficients, NA is plotted against temperature for different bend radii in Fig. 4. It can be seen that the NA temperature sensitivity decreases as the bend radius, $\mathrm{R}$, increases up to the NA temperature sensitivity for a $\mathrm{R}$ of $25 \mathrm{~mm}$.

For small amplitude variations in the core radius, the ratio of output to input power at the bend sensor $(\eta)$ is given by [25]:

$$
\eta=\frac{\mathrm{P}_{\text {Out }}}{\mathrm{P}_{\text {In }}}=\frac{\left.\left[\mathrm{n}_{\text {Core }}^{2}(\mathrm{~T})-\mathrm{n}_{\text {Cladding }}^{2}(\mathrm{~T})\right]\right|_{\text {Bend region }}}{\left.\left[\mathrm{n}_{\text {Core }}^{2}(\mathrm{~T})-\mathrm{n}_{\text {Cladding }}^{2}(\mathrm{~T})\right]\right|_{\text {Straight region }}}
$$

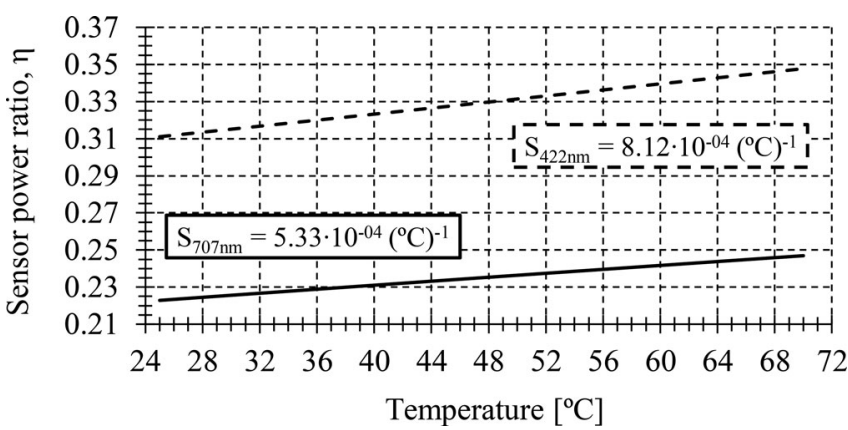

Fig. 5. Power ratio versus temperature in a bend fiber, $\mathrm{R}=2 \mathrm{~mm}, \varphi=135^{\circ}$ and $\rho=490 \mu \mathrm{m}:-\lambda=422 \mathrm{~nm},--\lambda=707 \mathrm{~nm}$.

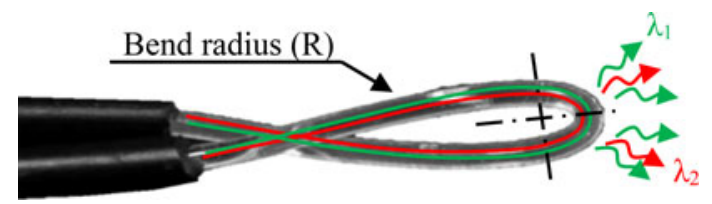

Fig. 6. Schematic of the two colors macrobend POF sensor.

where $\mathrm{P}_{\mathrm{Out}}$ is the output power in the bent region and $\mathrm{P}_{\mathrm{In}}$ is the input power, corresponding to the output of a straight region at $\mathrm{c}_{0}$, see Fig. 1. Insertion losses, fiber attenuation and other parameters of the system are not included. The power ratio versus temperature for different wavelengths is plotted in Fig. 5. The power ratio increases when temperature increases as demonstrated in [6].

\section{Manufactured sensor}

A schematic of the manufactured fiber-optic temperature sensor is shown in Fig. 6.

The PMMA-based POF used in the experiment allows a minimum bend radius of $25 \mathrm{~mm}$ [20]. This means that the losses are negligible when the fiber is bent with a radius above $25 \mathrm{~mm}$. The tensile strength and the Young's modulus are $70 \mathrm{~N}$ and $2.7 \mathrm{GPa}$ [20], [26], respectively. These characteristics provide good mechanical properties at the time of manufacturing the sensor and permit to bend the fiber below the minimum bend radius without break, despite of the attenuation increments. From the middle section of the fiber length, the buffer coating is partially stripped in section of $30 \mathrm{~mm}$ length. The sensor is formed by creating a single $180^{\circ}$ loop with a bend radius of $2 \mathrm{~mm}$, as shown in Fig. 6 . To fix the radius, a cylinder is used to give more precision to the bending process. Then, the buffer coating in the junction of the two branches is fixed by cyanoacrylate adhesive.

\section{Experimental set-up and measurements}

The schematic of the experimental set-up is shown in Fig. 7. The light source is a 360 to $2,500 \mathrm{~nm}$ stabilized halogen bulb. In order to overcome the low power of the halogen light source at short wavelengths, a 400 to $460 \mathrm{~nm}$ light-emitting diode (LED) IF-E92 is added to the main light source using collimating optics and a 50/50 POF splitter, as shown in Fig 8. The sensor is fixed at a $1 \mathrm{~mm}$ distance from a rectangular highly conductive metal base 


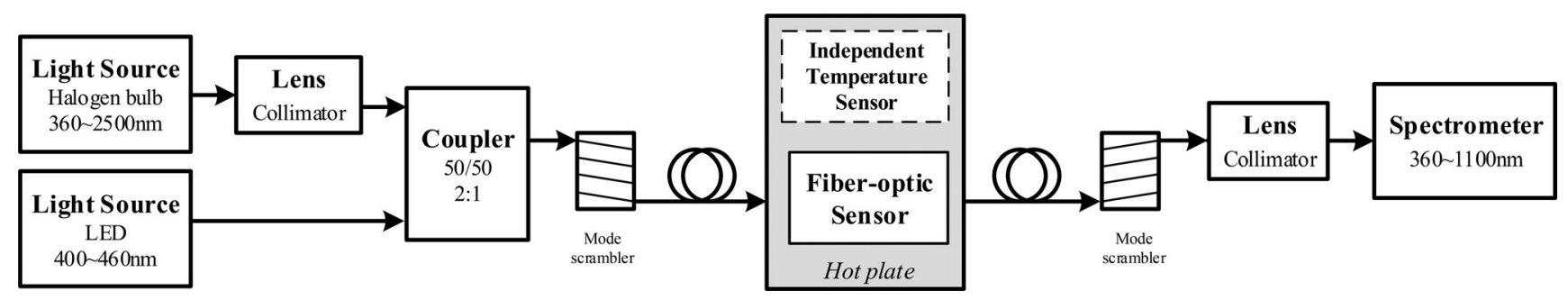

Fig. 7. Schematic of the experimental set-up for characterizing the POF temperature sensor.

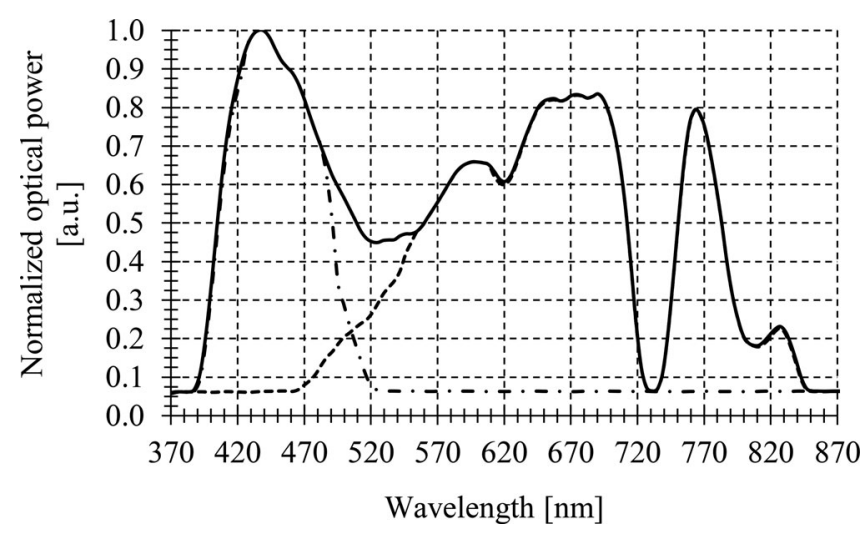

Fig. 8. Normalized power spectrum at the output branch of the coupler: Halogen bulb and LED, -- - Halogen bulb, - - - LED.

plate of the heating unit. A thermal isolated stage is performed for supporting the fiber sensor. Setting a fixed distance between the sensor and the hot plate prevents possible changes in the refractive index of the cladding due to the contact with other materials [6]. The temperature of the hot plate is controlled with a controller unit. For calibration purposes, an independent electronic temperature sensor is used.

Two mode scramblers are placed before and after the sensor to produces a stable mode distribution in the fiber regardless of the launch conditions.

All transmittance measurements are taken with a high speed diffraction grating based spectrometer with an array of 128 photodiodes (pixels), in the range from 360 to $886 \mathrm{~nm}$ and wavelength resolution of about $4 \mathrm{~nm}$. The spectrometer sensitivity is controlled by the integration time which can vary from $1 \mathrm{~ms}$ to 60s [27].

In order to avoid false reading caused by fluctuations of the light source or other undesired losses, a relation between transmittances at two different wavelengths $\left(\lambda_{1}, \lambda_{2}\right)$ is measured to implement a self-referencing technique. This transmittance ratios at the selected wavelengths $\left(\tau \lambda_{1}, \tau \lambda_{2}\right)$ are given by:

$$
\begin{aligned}
\tau_{\lambda_{1}} & =\frac{\mathrm{P}_{\lambda_{1}}(\mathrm{~T})}{\mathrm{P}_{\text {Ref }, \lambda_{1}}} \\
& =\frac{\mathrm{L}_{\mathrm{Dev}, \lambda_{1}} \cdot \mathrm{L}_{\text {Sensor }, \lambda_{1}}\left(\mathrm{~T}_{0}\right) \cdot \mathrm{F}_{\lambda_{1}}(\mathrm{~T}) \cdot \mathrm{P}_{\text {Source }, \lambda_{1}}}{L_{\mathrm{Dev}, \lambda_{1}} \cdot \mathrm{P}_{\text {Source }, \lambda_{1}}}= \\
& =\mathrm{L}_{\text {Sensor }, \lambda_{1}}\left(\mathrm{~T}_{0}\right) \cdot \mathrm{F}_{\lambda_{1}}(\mathrm{~T})
\end{aligned}
$$

$$
\begin{aligned}
\tau_{\lambda_{2}} & =\frac{\mathrm{P}_{\lambda_{2}}(\mathrm{~T})}{\mathrm{P}_{\mathrm{Ref}, \lambda_{2}}} \\
& =\frac{\mathrm{L}_{\mathrm{Dev}, \lambda_{2}} \cdot \mathrm{L}_{\mathrm{Sensor}, \lambda_{2}}\left(\mathrm{~T}_{0}\right) \cdot \mathrm{F}_{\lambda_{2}}(\mathrm{~T}) \cdot \mathrm{P}_{\text {Source }, \lambda_{2}}}{\mathrm{~L}_{\mathrm{Dev}, \lambda_{2}} \cdot \mathrm{P}_{\mathrm{Source}, \lambda_{2}}}= \\
& =\mathrm{L}_{\mathrm{Sensor}, \lambda_{2}}\left(\mathrm{~T}_{0}\right) \cdot \mathrm{F}_{\lambda_{2}}(\mathrm{~T})
\end{aligned}
$$

where $P \lambda_{1}(T)$ and $P \lambda_{2}(T)$ are the output optical power at each wavelength for a given temperature (T). $\mathrm{P}_{\text {Ref }}, \lambda_{1}$ and $\mathrm{P}_{\mathrm{Ref}}, \lambda_{2}$ are the output reference power for each wavelength at reference temperature.

These values are obtained measuring the output power for each wavelength without the macrobend optical fiber sensor in the calibration set-up. The integration time of the spectrometer is fixed at $300 \mathrm{~ms}$. The experiment is performed at reference temperature $\mathrm{T}_{0}$ of $25{ }^{\circ} \mathrm{C}$. $\mathrm{L}_{\mathrm{Dev}}, \lambda_{1}$ and $\mathrm{L}_{\mathrm{Dev}}, \lambda_{2}$ are factors including the attenuation of the fiber leads, collimation losses, connectors and adaptor losses and insertion losses of the coupler at each wavelength. $\mathrm{F} \lambda_{1}(\mathrm{~T})$ and $\mathrm{F} \lambda_{2}(\mathrm{~T})$ are the optical power modulation function versus temperature at the fiber-optic sensor for each wavelength. $\mathrm{L}_{\mathrm{Sensor}}, \lambda_{1}\left(\mathrm{~T}_{0}\right)$ and $\mathrm{L}_{\mathrm{Sensor}}, \lambda_{2}\left(\mathrm{~T}_{0}\right)$ are the macrobend sensor insertion losses at the reference temperature at both wavelengths. Finally, $\mathrm{P}_{\text {Source, }} \lambda_{1}$ and $\mathrm{P}_{\text {Source, }} \lambda_{2}$ are the optical power of the light source at the two selected wavelengths, respectively. From (7) and (8), the self-reference output transmittance ratio $\left(\gamma_{\mathrm{SR}}\right)$ is defined as:

$$
\begin{aligned}
\gamma_{\mathrm{SR}} & =\frac{\tau_{\lambda_{1}}}{\tau_{\lambda_{2}}}=\frac{\mathrm{L}_{\text {Sensor }, \lambda_{1}}\left(\mathrm{~T}_{0}\right) \cdot \mathrm{F}_{\lambda_{1}}(\mathrm{~T})}{\mathrm{L}_{\mathrm{Sensor}, \lambda_{2}}\left(\mathrm{~T}_{0}\right) \cdot \mathrm{F}_{\lambda_{2}}(\mathrm{~T})} \\
& =\frac{\mathrm{L}_{\text {Sensor }, \lambda_{1}}\left(\mathrm{~T}_{0}\right)}{\mathrm{L}_{\text {Sensor }, \lambda_{2}}\left(\mathrm{~T}_{0}\right)} \cdot F(\mathrm{~T})
\end{aligned}
$$

The self-reference output transmittance ratio depends on the power sensor variations with temperature and on a constant ratio between the insertion losses of the macrobend sensor at the different wavelengths.

In the experiment, the transmittance at different wavelengths is measured from 370 to $870 \mathrm{~nm}$ with $4 \mathrm{~nm}$ resolution using the spectrometer, in a temperature range from 27 to 70 ${ }^{\circ} \mathrm{C}$ at $2{ }^{\circ} \mathrm{C}$ intervals. A time interval of $2 \mathrm{~min}$ is set, between each temperature measurement, to ensure the stabilization of the transmittance values. In those measurements, the spectrometer integration time is adjusted from $300 \mathrm{~ms}$ to $3 \mathrm{~s}$ in order to compensate the sensor insertion loss, of $10 \mathrm{~dB}$ including the ST connectors. It is recommended that the spectral measurements cover $90 \%$ of the spectrometer's full scale [27]. A total of five 


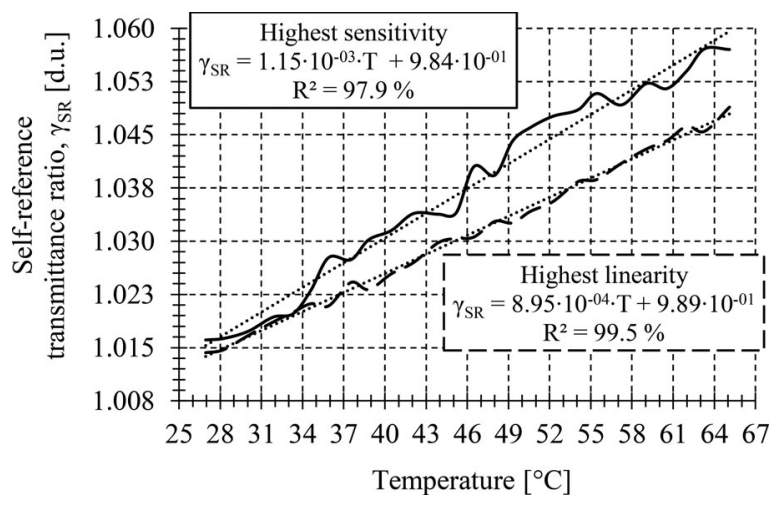

Fig. 9. Self-reference transmittance ratio versus temperature: $422 / 409 \mathrm{~nm},---707 / 779 \mathrm{~nm}$.

samples for each wavelength and temperature are carried out to perform a complete statistical analysis of the sensor parameters. Software based on graphical programming code is developed to acquire transmittance from the spectrometer.

A searching algorithm based on numerical computing code has been developed to find the output transmittance ratios that offer the highest linearity and sensitivity for all possible pair of wavelengths. The analyzed wavelengths are located in spectral regions of low POF attenuation. For each temperature and wavelength, the algorithm calculates the mean of the transmittances for the five samples. The ratio of the average transmittance at two different wavelengths is calculated for each temperature. This value is estimated for all pairs of wavelengths. The sensitivity and the linear regression coefficient are calculated for each transmittance ratio using a linear regression model to approach the relationship between transmittance and temperature.

Fig. 9 shows the measurements of the calibration curves for the two pairs of wavelengths that offer the highest linear regression and sensitivity. These sensitivities are $8.95 \cdot 10^{-4}{ }^{\circ} \mathrm{C}^{-1}$ for $707 / 779 \mathrm{~nm}$ transmission ratio, and $1.15 \cdot 10^{-3}{ }^{\circ} \mathrm{C}^{-1}$ for $422 / 409 \mathrm{~nm}$ transmission ratio. These values can be expressed as $3.82 \cdot 10^{-3}$ and $4.49 \cdot 10^{-3} \mathrm{~dB} /{ }^{\circ} \mathrm{C}$. The sensor temperature sensitivity is higher than the temperature coefficient of the fiber attenuation $\beta_{\mathrm{R}}=1.510^{-6} \mathrm{~dB} /{ }^{\circ} \mathrm{C}$, for a $3 \mathrm{~cm}$ long POF sensor [24]. The linear regression coefficients are 99.5 and $97.9 \%$, respectively. The full-scale self-reference transmittance ratio errors are 2.6 and $3.2 \%$, respectively. The sensor precision is calculated from the maximum standard deviation of the five samples for each temperature. The self-reference transmittance ratio accuracy for $707 / 779 \mathrm{~nm}$ and $422 / 409 \mathrm{~nm}$ is 0.1 and $0.2 \%$, respectively. The fiber attenuation at 409, 422, 707 and $779 \mathrm{~nm}$ is $0.19,0.16,0.83$ and $0.87 \mathrm{~dB} / \mathrm{m}$, respectively.

The sensitivity of the transmittance ratios at the two pairs of wavelengths increases at shorter wavelengths due to the decrement of the NA variation with temperature at longer wavelengths, as expected from Fig. 3. This is also shown in Fig. 10, where output transmittance measurements are plotted against temperature for different wavelengths. Therefore, the measured wavelength dependence of the sensor is in good agreement with theory. Specific simulations for a single wavelength using the ray tracing theory are reported in [6].

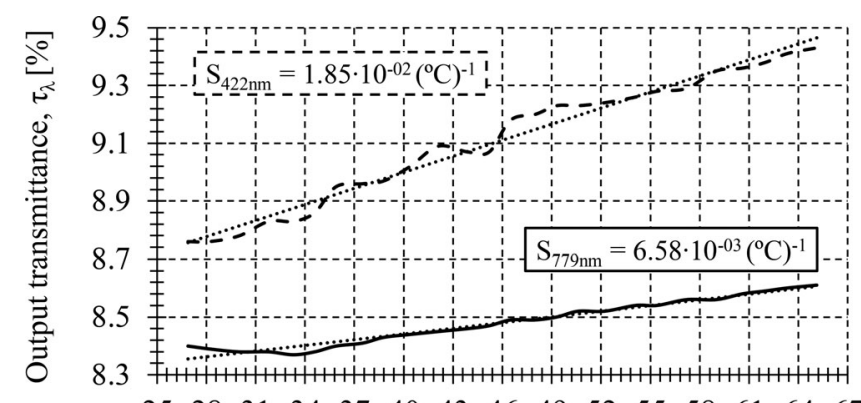

$\begin{array}{lllllllllllllll}25 & 28 & 31 & 34 & 37 & 40 & 43 & 46 & 49 & 52 & 55 & 58 & 61 & 64 & 67\end{array}$

Temperature $\left[{ }^{\circ} \mathrm{C}\right]$

Fig. 10. Output transmittance versus temperature: $---422 \mathrm{~nm},-779 \mathrm{~nm}$.

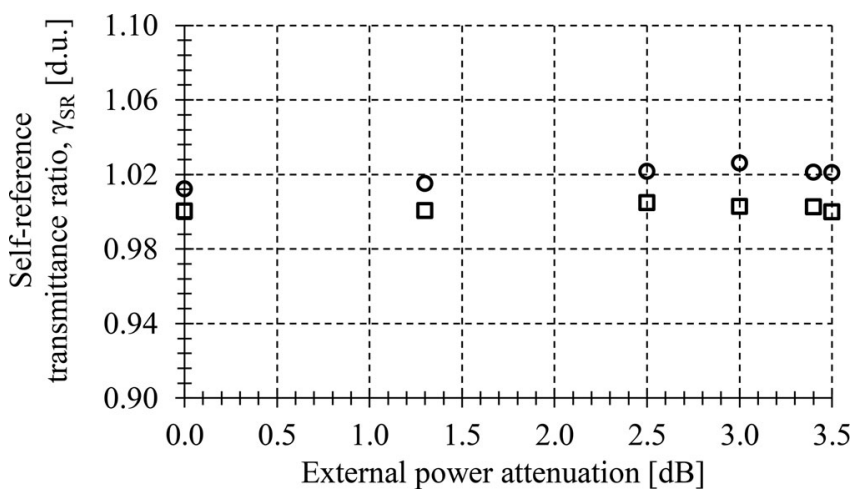

Fig. 11. Self-reference transmittance ratio $\gamma_{\mathrm{SR}}$, versus undesirable power fluctuations: $\circ 422 / 409$ (Highest sensitivity), $\square$ 707/779 (Highest linearity)

\section{Self-referencing test}

The self-reference property is tested by inducing power fluctuations through a mandrel. Measurements are taken for the highest linearity and sensitivity curves, see Fig. 11.

The self-reference transmittance ratio error from external power fluctuations at a fixed temperature is 0.2 and $0.5 \%$ for $707 / 779 \mathrm{~nm}$ and $422 / 409 \mathrm{~nm}$, respectively. As expected, the self-reference transmittance ratio errors for the sensor calibration curves are higher than those for the self-reference test. There are no significant changes in the measurement parameter after inducing a power attenuation up to $3.5 \mathrm{~dB}$.

\section{Discussion}

The proposed temperature sensor uses the ratio of transmittance at two different wavelengths to provide a robust wavelength division multiplexing (WDM) self-referencing technique. An experiment is carried out for measuring the transmittance from 370 to $870 \mathrm{~nm}$. The output transmittance ratio measurements for all possible those wavelengths are calculated to find those wavelengths that offers the highest linearity and good sensitivity. Those are $\lambda_{1}=707 \mathrm{~nm}$ and $\lambda_{2}=779 \mathrm{~nm}$. The sensor can operate in a temperature range from -55 to $70{ }^{\circ} \mathrm{C}$. Meanwhile the measured calibration curve from 27 to $70{ }^{\circ} \mathrm{C}$, shows a sensitivity and a linear regression coefficient of $8.95 \cdot 10^{-4}{ }^{\circ} \mathrm{C}^{-1}$ and $99.5 \%$, respectively. The self-reference transmission ratio 


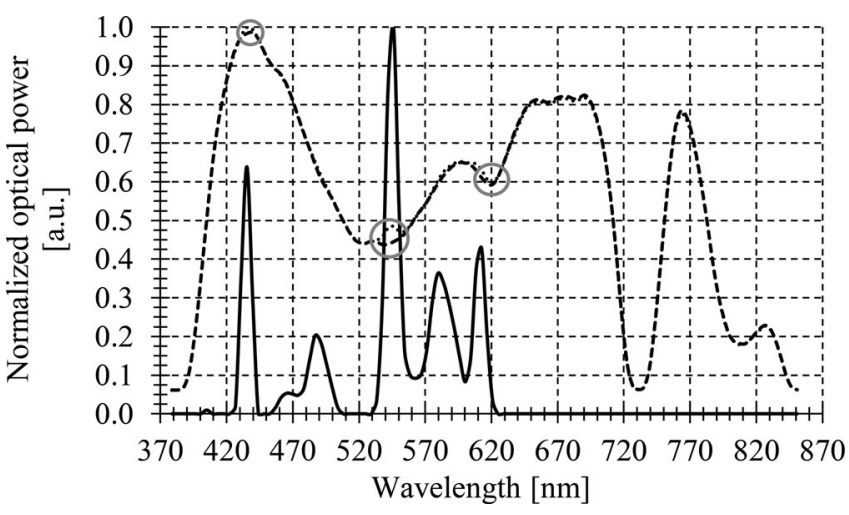

Fig. 12. Normalized power spectrum: —— Fluorescent light emission spectrum, --- Sensor output power without fluorescent light, $\cdots$ Sensor output power with fluorescent light.

accuracy and full-scale temperature precision error are 0.1 and $6 \%$, respectively.

The most limiting component in the system error is the spectrometer. The spectrometer used in this experiment has a transmittance ratio repeatability error and resolution of 0.17 and $0.002 \%$ for $707 / 779 \mathrm{~nm}$. By using another spectrometer with higher intensity resolution and sensitivity, the system temperature error and the oscillations of the self-reference parameter can be reduced.

The sensor can be used under ambient lighting conditions, such as fluorescent ceiling lamps. Fig. 12 shows the influence of the fluorescent light emission spectrum on the sensor. Appreciable change on the sensor output power spectrum occurs at the maximum power peaks of fluorescent light emission spectrum but outside of the maximum sensitivity and linearity wavelength ranges. This demonstrates that there is no influence of fluorescent light in the measurement process.

Measurements presented in this work are performed using a stabilized halogen light source in combination with a blue LED, in order to compensate the low power of the halogen source in the violet-blue region (see Fig. 8).

The output power of the blue LED is not stabilized. Voltage changes in the DC power supply may present power drift with time. The calibration curve is measured 120 min after turning on the sources and the measurements take $50 \mathrm{~min}$. An analysis of the output transmittance ratio is carried out to ensure the stability of the measurements. The blue LED has a power drift of $0.03 \%$ for $422 / 409 \mathrm{~nm}$ transmission ratio during the $50 \mathrm{~min}$ test. To measure the power drift the LED was thermally stabilized using a thermal hot plate at $25^{\circ} \mathrm{C}$. On the other hand, when measuring the sensor calibration curve, the LED is not thermally stabilized and may present a power drift with ambient temperature. During the measurements, the ambient temperature changed between 25 and $26^{\circ} \mathrm{C}$. Considering these values, the power drift is $0.05 \%$ for $422 / 409 \mathrm{~nm}$ transmission ratio. Using the calibration curve at the selected ratio of transmittances, this value can be expressed in terms of full-scale temperature errors as $1.7 \%$. These results justify the higher temperature error for the 422/409 transmission ratio calibration curve. The use of a thermally and power stabilized halogen light source reduces the sensor temperature error.
A comparative analysis has been developed between the proposed technique and other implementations of WDM selfreferencing techniques reported on the literature, see Table II.

Self-referencing techniques based on silica fiber [28], [29] require more expensive and accurate equipment than those based on POF. This is due to the smaller size and lower NA of the silica fibers. Some self-reference techniques [29], [30] use a modulated optical signal at a low frequency for improving the resolution but at the expense of increasing the cost and the complexity of the system. POF sensor reported in [6] uses a selfreferencing technique that needs a dummy sensor. The main drawbacks to use a dummy sensor are the fact that the reference signal and the sensing signal follow different paths and the need to add an additional sensor. The optical power at those two paths could be affected by different short or long term power perturbations, changing the output power ratio and hence the reading temperature. On the other hand, the tolerances of the sensor manufacturing process can make difficult to manufacture two identical sensors in a repetitive way. To overcome these problems, a WDM self-referencing technique based on a single macro-bend loop is proposed. This technique has smaller fluctuations of the self-reference parameter in comparison with other implementations, see Table II. Anyway, this technique usually requires the use of demultiplexers to measure the transmittance at each wavelength as those reported in [31].

One potential application field of the proposed temperature sensor is in the biomedical sector. Minimally invasive tools and sensors have become essential for medical diagnosis and surgery with the desire of not only serving at the same time to sense physiological parameters, but also being able to overcome biocompatibility concerns. Nowadays, there are different medical areas where fiber-optic temperature sensors hold potential; particularly if in-vivo applications are pursued [32], as here there is a need to develop sensors for minimally invasive surgery procedures. The minimum and maximum temperature that a human body can stand without dying are approximately $20{ }^{\circ} \mathrm{C}$ [33] and $41.1{ }^{\circ} \mathrm{C}$ [34]. According to this temperature range, the proposed sensor can be used in medical applications.

On the other hand, the proposed fiber-optic sensor can be used in temperature measurements in power transformer applications where the presence of electromagnetic interferences limits the use of traditional sensors [35]. The current demand of energy requires an overload in the transformers causing overheating in the refrigerant liquid. The coolant aging increases the risk of in-service failure, being potentially dangerous through explosions and fire, is costly to repair or replace, and may result in significant loss of revenue [36]. The working temperature range of a transformer oil is from $20^{\circ} \mathrm{C}$ to $45^{\circ} \mathrm{C}$ [35]. For this reason, the proposed POF temperature sensors can be a good solution.

\section{Conclusion}

Macrobending loss, caused by the changes in the core and cladding refractive indexes of a SI POF has shown to be a usable technique for temperature sensing at different wavelengths. A WDM self-referencing technique has shown to provide a robust temperature sensor development independent of the 
TABLE II

CHARACTERISTICS IN SOME INTENSITY BASED SENSORS

\begin{tabular}{|c|c|c|c|c|c|c|}
\hline $\begin{array}{l}\text { Self-Reference } \\
\text { Technique }\end{array}$ & Fiber & Light Source & Modulated & $\begin{array}{l}\text { Wavelength } \\
\text { demultiplexing }\end{array}$ & Detector & $\begin{array}{l}\text { Self-Reference parameter } \\
\text { (1) }\end{array}$ \\
\hline $\begin{array}{l}\text { WDM Technique } \\
{[28]}\end{array}$ & $\begin{array}{l}\text { Graded-index } \\
\text { Silica Fiber }\end{array}$ & $\begin{array}{l}\text { White light } \\
\text { source }\end{array}$ & $\begin{array}{c}\text { Non- } \\
\text { modulated }\end{array}$ & $\begin{array}{l}\text { Two bandpass } \\
\text { filters and a } \\
\text { beam splitter }\end{array}$ & $\begin{array}{c}\text { Two } \\
\text { photodetectors }\end{array}$ & $\begin{array}{l}\sim 5 \% \text { fluctuation after } \\
\text { inducing } 3 \mathrm{~dB} \text { external loss }\end{array}$ \\
\hline $\begin{array}{l}\text { WDM Technique } \\
\text { [29] }\end{array}$ & $\begin{array}{l}\text { Step-index } \\
\text { Silica Fiber }\end{array}$ & GaAlAs LED & Square $1 \mathrm{kHz}$ & $\begin{array}{l}\text { Two optical } \\
\text { filters and a } \\
\text { beam splitter }\end{array}$ & $\begin{array}{c}\text { Two PIN } \\
\text { photodiodes }\end{array}$ & $\begin{array}{l}\sim 1 \% \text { fluctuation after } \\
\text { coiling the fiber into } 5 \text { loops } \\
\text { of } 1 \mathrm{~cm}\end{array}$ \\
\hline $\begin{array}{l}\text { WDM Technique } \\
{[30]}\end{array}$ & $\begin{array}{l}\text { Step-index } \\
\text { PMMA POF }\end{array}$ & $\begin{array}{l}\text { Multicolor (blue } \\
\text { and red) LED }\end{array}$ & ASK 1 kHz (4) & $\begin{array}{l}\text { Synchronous } \\
\text { detection } \\
\text { algorithm }\end{array}$ & $\begin{array}{c}\text { One } \\
\text { photodetector }\end{array}$ & $\begin{array}{c}\sim 1.5 \% \text { fluctuation after } \\
\text { inducing } 0.42 \mathrm{~dB} \text { external } \\
\text { loss }\end{array}$ \\
\hline $\begin{array}{l}\text { Dummy sensor } \\
\text { [6] }\end{array}$ & $\begin{array}{l}\text { Step-index } \\
\text { PMMA POF }\end{array}$ & Red LED & $\begin{array}{l}\text { Non- } \\
\text { modulated }\end{array}$ & $\begin{array}{l}\text { Two different } \\
\text { paths }\end{array}$ & $\begin{array}{c}\text { Two Si } \\
\text { photodetectors }\end{array}$ & (2) \\
\hline $\begin{array}{l}\text { WDM Technique } \\
\text { (This work) }\end{array}$ & $\begin{array}{l}\text { Step-index } \\
\text { PMMA POF }\end{array}$ & $\begin{array}{l}\text { Halogen bulb and } \\
\text { blue LED }\end{array}$ & $\begin{array}{l}\text { Non- } \\
\text { modulated }\end{array}$ & $\begin{array}{l}\text { Spectrometer } \\
\text { (3) }\end{array}$ & $\begin{array}{l}\text { Spectrometer } \\
\text { (3) }\end{array}$ & $\begin{array}{l}0.2 \% \text { fluctuation after } \\
\text { inducing } 3.5 \mathrm{~dB} \text { external loss }\end{array}$ \\
\hline
\end{tabular}

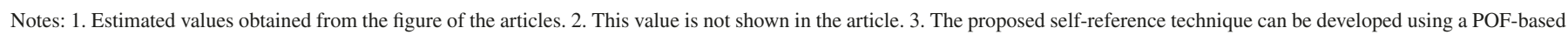
demultiplexer [31] and two Si photodiodes to reduce its cost. 4. ASK: Amplitude-shift keying.

repeatability of the manufacturing process and the different physical path loss evolution of other self-referencing techniques. The sensitivity increases as the wavelengths used to calculate the self-reference transmittance ratio decreases. Moreover, longer wavelengths induce a lower temperature error and a higher linearity. The self-reference sensor based on the transmittance ratio at $\lambda_{1}=707 \mathrm{~nm}$ and $\lambda_{2}=779 \mathrm{~nm}$ has a sensitivity of $8.95 \cdot 10^{-4}$ ${ }^{\circ} \mathrm{C}^{-1}$. The linear regression coefficient is $99.5 \%$. It shows a $6 \%$ full-scale temperature error due to the spectrometer used in the experiments. The proposed sensor is based on a single macrobend loop on flexible and easy to handle fiber using low-cost optical sources. The sensor can be used in power transformer and biomedical applications.

\section{References}

[1] V. Busurin, A. S. Semenov, and N. Udalov, "Optical and fiber-optic sensors (review)," Soviet J. Quantum Electron., vol. 15, no. 5, pp. 595, 2007.

[2] Y. Wang, Y. Li, C. Liao, D. N. Wang, M. Yang, and P. Lu, "Hightemperature sensing using miniaturized fiber in-line Mach-Zehnder interferometer," IEEE Photon. Tech. Lett., vol. 22, no. 1, pp. 39-41, Nov. 2009.

[3] H. Y. Choi, K. S. Park, S. J. Park et al., "Miniature fiber-optic high temperature sensor based on a hybrid structured Fabry-Perot interferometer," Opt. Lett., vol. 33, no. 21, pp. 2455-2457, 2008.

[4] M. Corke, A. Kersey, D. Jackson et al., "All-fibre 'Michelson'thermometer," Electron. Lett., vol. 19, no. 13, pp. 471-473, 1983.

[5] G. Betta and A. Pietrosanto, "An intrinsic fiber optic temperature sensor," IEEE Trans. Instrum. Meas., vol. 49, no. 1, pp. 25-29, Feb. 2000.

[6] A. Tapetado, C. Vázquez, J. Zubia et al., "A temperature sensor based on a polymer optical fiber macro-bend," Sensors, vol. 13, no. 10, pp. 13076-13089, 2013

[7] G. Rajan, Y. Semenova, and G. Farrell, "All-fibre temperature sensor based on macro-bend single mode fibre loop," Electron. Lett., vol. 44, no. 19, pp. 1123-1124, 2008.

[8] B. Müller and U. Renz, "Time resolved temperature measurements in manufacturing," Measurement, vol. 34, no. 4, pp. 363-370, 2003.

[9] K. Kyuma, S. Tai, T. Sawada, and M. Nunoshita, "Fiber-optic instrument for temperature measurement," IEEE Trans. Microw. Theory Tech., vol. MTT-30, no. 4, pp. 522-525, Apr. 1982.

[10] D. S. Montero, C. Vázquez, J. Baptista et al., "Coarse WDM networking of self-referenced fiber-optic intensity sensors with reconfigurable characteristics," Opt. Exp., vol. 18, no. 5, pp. 4396-4410, 2010.

[11] D. S. Montero, C. Vázquez, I. Möllers et al., "A self-referencing intensity based polymer optical fiber sensor for liquid detection," Sensors, vol. 9, no. 8, pp. 6446-6455, 2009.
[12] G. Murtaza and J. Senior, "Referencing strategies for intensity modulated optical fibre sensors: a review," Opt. Laser Tech., vol. 25, no. 4, pp. 235246, 1993.

[13] C. Vázquez, J. Montalvo, and P. C. Lallana, "Radio-frequency ring resonators for self-referencing fiber-optic intensity sensors," Opt. Eng., vol. 44, no. 4, p. 040502, 2005.

[14] M. L. Casalicchio, M. Olivero, G. Perrone et al., "Plastic optical fiber sensor for displacement monitoring with dual-wavelength compensation of power fluctuations," in Proc. Instrum. Meas. Tech. Conf., 2011, pp. $1-5$.

[15] S. Tao and A. Jayaprakash, "A fiber optic temperature sensor with an epoxy-glue membrane as a temperature indicator," Sensors Actuators B: Chemical, vol. 119, no. 2, pp. 615-620, 2006.

[16] G. Rajan, Y. Semenova, P. Wang, and G. Farrell, "Temperature-induced instabilities in macro-bend fiber based wavelength measurement systems," J. Lightw. Tech., vol. 27, no. 10, pp. 1355-1361, Apr. 2009.

[17] A. Tapetado, P. Pinzón, J. Zubia et al., "Self-referenced temperature sensor based on a polymer optical fiber macro-bend," in Proc. 23rd Int. Conf. Opt. Fiber Sensors, 2014, pp. 915716-1-915716-4.

[18] M. Remouche, R. Mokdad, A. Chakari et al., "Intrinsic integrated optical temperature sensor based on waveguide bend loss," Opt. Laser Tech., vol. 39, no. 7, pp. 1454-1460, 2007.

[19] M. Remouche, F. Georges, and P. Meyrueis, "Flexible optical waveguide bent loss attenuation effects analysis and modeling application to an intrinsic optical fiber temperature sensor," Opt. Photon. J., vol. 2, no. 1, pp. $1-7,2012$.

[20] M. Rayon. (2015, Jan. 8). Specification sheet high-performance plastic optical fiber Eska SH-4001. [Online]. Available: http://www. pofeska.com/pofeskae/download/pdf/c/GH4001.pdf

[21] J. W. Fleming, "Material dispersion in lightguide glasses," Electron. Lett., vol. 14 , no. 11, pp. 326-328, 1978

[22] T. Ishigure, E. Nihei, and Y. Koike, "Optimum refractive-index profile of the graded-index polymer optical fiber, toward gigabit data links," Appl. Opt., vol. 35, no. 12, pp. 2048-2053, 1996.

[23] A. E.-N. A. Mohammed, M. M. El-Halawany, A. N. Z. Rashed et al., "High performance of plastic optical fibers within conventional amplification technique in advanced local area optical communication networks," Int. J. Multidisciplinary Sci. Eng., vol. 2, no. 2, pp. 34-42, 2011.

[24] Y. Tsukamoto, (Personal communication), Plastic Molding Dept., Fiber Optics Section, Mitsubishi Rayon Co. Ltd., Tokyo, Japan, Apr. 4, 2013.

[25] J. Zubia and J. Arrue, "Plastic Optical Fibers: An introduction to their technological processes and applications," Opt. Fiber Tech., vol. 7, no. 2, pp. 101-140, 2001.

[26] D. X. Yang, J. Yu, X. Tao et al., "Structural and mechanical properties of polymeric optical fiber," Mater. Sci. Eng.: A, vol. 364, no. 1-2, pp. 256-259, Jan. 15, 2004.

[27] Avantes Solutions in Spectroscopy. (2015, Jan 11). AvaSpec-128 StarLine ultrafast fiber-optic spectrometer. [Online]. Available: http:// www.avantes.com/images/stories/brochurescat2012/28-29_-_avaspec128.pdf 
[28] A. Wang, G. Z. Wang, K. A. Murphy et al., "Fiber-optic temperature sensors based on differential spectral transmittance/reflectivity and multiplexed sensing systems," Appl. Opt, vol. 34, no. 13, pp. 2295-2300, 1995.

[29] J. M. Senior, G. Murtaza, A. I. Stirling et al., "Single LED based dual wavelength referenced optical fibre sensor system using intensity modulation," Opt. Laser Tech., vol. 24, no. 4, pp. 187-192, 1992.

[30] A. Vallan, M. L. Casalicchio, M. Olivero, and G. Perrone, "Assessment of a dual-wavelength compensation technique for displacement sensors using plastic optical fibers," IEEE Tran. Instrum. Meas., vol. 61, no. 5, pp. 1377-1383, Jan. 2012.

[31] O. Ziemann, J. Krauser, P. E. Zamzow et al., POF Handbook: Optical Short Range Transmission Systems, New York, NY, USA: Springer, 2008, pp. 507-528.

[32] D. J. Webb, S. Jones, L. Zhang et al., "First in-vivo trials of a fiber Bragg grating based temperature profiling system," J. Biomed. Opt., vol. 5, no. 1, pp. 45-50, 2000.
[33] B. W. Trautner, A. C. Caviness, G. R. Gerlacher et al., "Prospective evaluation of the risk of serious bacterial infection in children who present to the emergency department with hyperpyrexia (temperature of $106 \mathrm{~F}$ or higher)," Pediatrics, vol. 118, no. 1, pp. 34-40, 2006.

[34] D. F. Danzl and R. S. Pozos, "Accidental Hypothermia," New Engl. J. Med., vol. 331, no. 26, pp. 1756-1760, 1994.

[35] B. C. Lesieutre, W. H. Hagman and J. L. Kirtley Jr., "An improved transformer top oil temperature model for use in an on-line monitoring and diagnostic system," IEEE Tran. Power Del., vol. 12, no. 1, pp. 249-256, Jan. 1997.

[36] M. Wang, A. J. Vandermaar and K. D. Srivastava, "Review of condition assessment of power transformers in service," IEEE Electr. Insul. Mag., vol. 18, no. 6, pp. 12-25, Nov.-Dec. 2002. 